\title{
Innovative Active Cross-Linking Agents for Sustainable Leather Manufacturing
}

\author{
V. Beghetto $^{* 1,2}$ L. Agostinis ${ }^{1}$, R. Taffarello ${ }^{2}$, R. Samiolo ${ }^{2}$ \\ ${ }^{1}$ Department of Molecular Sciences and Nanosystems, University Ca' Foscari of Venice, Via \\ Torino 155, 30172 Venice, ITALY \\ beghettodunive.it, lodovico.agostinis@hotmail.com \\ ${ }^{2}$ Crossing S.r.l., Piazza delle Istituzioni n. 27 ed. H, 31100 Treviso, ITALY. \\ renzotaffarello@hotmail.com, riccardosamiolo@libero.it
}

\begin{abstract}
For the first time New Active Cross-Linking agents ( $\mathrm{ACL}$ ) have been tested to process hides demonstrating the possibility to produce good quality leather with a highly sustainable protocol. A comparison is made between ACL, chrome and other tanning agents commonly employed by the Leather Industry.
\end{abstract}

KEYWORDS: Leather, Cross-linking, Manufacturing industry Sustainable Development Sustainable Production

\section{Introduction}

Sustainability has become an important issue in all spheres of life, focusing on the safeguard of people's life, environmental protection and natural resources exploitation. Companies around the world are showing increasing interest in environmentally friendly manufacturing [1].

The leather industry is a world-wide leading market concerning the processing of skin or hide of animals, poses important quests regarding the environmental sustainability of the industrial process and waste management.

Currently, Asia and in particular China is the world leader in leather production, along with India and Hong Kong. However, according to market overviews, Italy leads both the garment and the fashion industries surpassing both Asia and South America [2]. According to 2013 Euroleather's report the turnover of the European tanning industry was estimated to be 7.8 billion Euros, corresponding to a production of 224 million $\mathrm{m}^{2}$ of finished leather a year. Only in Italy in 2011 the total amount of chemical products used by tanning industries was equivalent to 47 million tons/year (ca. 0.4

adfa, p. 1, 2011.

(C) Springer-Verlag Berlin Heidelberg 2011 
$\mathrm{Kg} / \mathrm{Kg}$ of leather produced). Of this amount $31 \%$ are products containing substances classified as hazardous, according to European standard (DIR 67/548 CEE).

The European production is responsible for $17 \%$ of the worldwide leather market. In 2013 according to UNIC (National Union of Tanning Industries), Italy has covered 62\% of the European production, $60 \%$ of which was processed by the Tannery District of Arzignano (TDA) and $30 \%$ by SCA corresponding to an annual turnover of 4.9 billion euro/year.

Generally, European tanneries are companies of small to medium size and are specialized in the production of all kinds of leather for different goods such as footwear, garment, furniture, automotive (Table 1). The consequent flexibility, adaptability and the quick response to demand constitutes one of the industry's most important assets.

Table 1. European leather market in 2009.

\begin{tabular}{llllll}
\hline 2009 & $\begin{array}{l}\text { Number } \\
\text { of employers }\end{array}$ & Companies & Exports & \multicolumn{2}{l}{ Production $\left(1.000 \mathrm{~m}^{2}\right)$} \\
& $1 \%)$ & Bovine & Sheep/Goat \\
\hline France & 1.529 & 53 & 33 & 2.663 & 2.306 \\
Germany & 1.925 & 18 & 60 & 7.000 & 450 \\
Italy & 16.717 & 1.378 & 68 & 96.921 & 29.295 \\
Netherlands & 325 & 5 & 71 & 4.000 & - \\
Portugal & 1.980 & 63 & 31 & - & - \\
Spain & 1.689 & 118 & 45 & 14.414 & 7.686 \\
Sweden & 260 & 4 & 90 & 1.100 & 30 \\
UK & 1.000 & 23 & 70 & 5.000 & 1.500 \\
Romania (est) & 900 & 15 & - & 300 & 1.250 \\
Bulgaria & 190 & 17 & 90 & 55 & 176 \\
Norway & 78 & 2 & - & - & - \\
TOTAL & 25.613 & 1.633 & & 131.453 & 42.693 \\
\hline
\end{tabular}

Nowadays, the average of bovine slaughtered Worldwide every year is roughly 300 million, corresponding to 15 million tons of hides. The leather industry transforms 
this waste into a valuable secondary material.

Nonetheless, leather manufacturing is water, energy and waste intensive and the tanning of hides is listed by the European Directive 96/61EC as an activity for which integrated prevention and control of pollution has to be achieved. Tannery effluents, if not properly treated, can cause serious damage to soil and water bodies.

Environmental concern clearly emerges from the European IPPC Bureau report 2013: at present over $85 \%$ of the world leather production is chrome tanned and only 20$25 \%$ in weight of raw bovine hides treated are transformed in final leather goods [3]. For $1000 \mathrm{Kg}$ of hides processed, only $250-300 \mathrm{Kg}$ of leather are produced, requiring $500 \mathrm{Kg}$ of chemical substances, $50 \mathrm{~m}^{3}$ of fresh water and generating ca. $600 \mathrm{Kg}$ of solid waste, with a production of chrome containing solid waste of ca. 400.000 ton/year in Europe.

Most of the steps of a tannery's operations are performed in water. Consequently, waste water is one of the major concerns in tanneries. The characteristics of untreated waste water are a high chemical and biochemical oxygen demand, and a high salt and process chemical content.

The use of chrome poses serious environmental and health problems, due to the formation of carcinogenic $\mathrm{Cr}(\mathrm{VI})$ in the finished articles and in the slurries, pushing the most important fashion groups and the manufacturers to find innovative solutions.

Cleaner, high exhaustion chrome tanning technologies exist and are used industrially today to reduce chromium in waste water, nevertheless they are inadequate to eliminate completely chrome from water effluents $[3,4]$.

The substitution of chromium tanning agents has been limited until today; no valid alternative has yet been found to the use of $\mathrm{Cr}(\mathrm{III})$ salts due its ease of use, low cost, high quality and stability of the tanned leather, and the characteristic "hand" imparted to the finished product.

Currently, the main alternatives used industrially to tan leather (synthetic, natural tannins or aldehydes) impart physical and mechanical characteristics significantly lower than Chrome, without, however, solving the problem of health for the con- 
sumer and the environment impact since from this leather formaldehyde (carcinogen) and phenol (cytotoxic) can be released [5]. Formaldehyde, employed for the production of many synthetic tannins, will be banned from use in January 2016 for its assessed carcinogenic activity, making the quest for a new tanning alternative to chrome even more urgent.

The work hereafter reported will highlight the general advantages of an innovative and revolutionary class of Tanning Agents referred to as ACL from "active crosslinking" agents which could become a viable alternative to chrome in the future.

\section{ACL LEATHER MANUFACTURING}

Before illustrating the new ACL protocol it is important to give a general and schematic description of hides processing from the moment they arrive in the industry up to the tanning phase.

Leather manufacturing may comprise up to 70 steps. The major processes are curing, soaking, flesh and hair removal, scudding, deliming, tanning, dyeing, rolling and finishing [5]. In the following the focus will be on the tanning step. The process, albeit its complexity, is very flexible and adaptable to different raw materials and to the final products wanted. In Scheme 1 are reported the first steps of the manufacturing process from soaking to tanning.

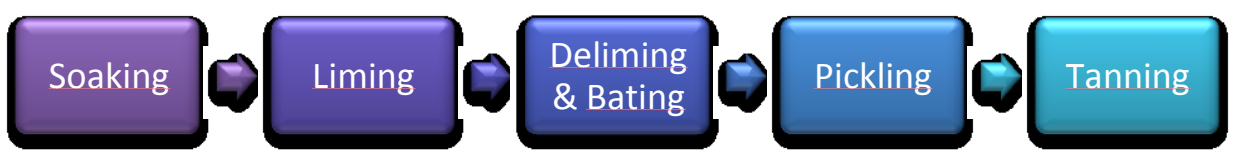

Scheme. 1. Simplified scheme of the tanning process.

In the first step of the process (soaking) the animal skins are soaked with water in the presence of additives in order to remove the excess of salt, blood, etc. and restore a suitable water content inside the hides [6]. In the second step (liming, dehearing) the soaked skins are treated with an alkali $\left(\mathrm{Ca}(\mathrm{OH})_{2}\right)$ and sulfide solution $\left(\mathrm{Na}_{2} \mathrm{~S}\right)$ to facili- 
tate hair removal and eliminate unwanted substances (non-structured proteins, fats, hyaluronic acid, etc.) [7]. The hide is now mainly constituted by collagen which is chemically modified and swells, leaving a more opened structure. Adhering flesh and subcutaneous tissue are mechanically cut off by fleshing. In the deliming and bating step (enzyme digestion) the skin structure is further opened up. Now hides need to be prepared for the tanning step by pickling; this specific step differs according to the specific tanning agent employed. All industrial protocols employed today require pickling.

Pickling is an acidic treatment carried out with mixtures of week and strong acids (formic and sulphuric acid are the most used) in the presence of sodium chloride, added to prevent a dangerous acid swelling of the pelt $[8,9]$. According to the specific tanning agent employed the $\mathrm{pH}$ may be higher or lower in a range between $2.5<\mathrm{pH}<$ 4.5. For historical reasons, all the preparative stages before the proper tanning step are collectively called beamhouse.

With the tanning process the skin is chemically stabilized and is converted into an imputrescible material due to the formation of interactions, bonds between the tanning agent and the collagen. The stability of the leather obtained after the tanning process can be ascribed to the chemical bonds formed between the collagen fibers of the hide and the tanning agent. Differential Scanning Calorimetry (DSC) is a widely used technique to evaluate the thermal stability of collagen after treatment, which is correlated to the cross-linking density within the collagen matrix. In particular, the DSC analysis of collagen typically shows a characteristic gelatinization temperature (Tg), originated by the transition from crystalline phase (triple helices) into amorphous random coils due to the breaking of inter-chain bonds [10].

The studies carried out by the group in the last years concern the innovative application of a class of chemical organic molecules used as activating cross-linking agents $(A C L)$, with the aim to develop the know-how for their production and use, in manufacturing industry (pending patent).

In particular, the idea takes birth from an intuition which transposes a pharmaceutical protocol to large scale manufacturing industry, for the production of leather but 
also other applications are under study for the production of preservative-packaging, antimicrobial fabrics, high fixation dyes, etc. The great potential of these molecules (commercially available and of new formulation) is embedded in their multiple applications. At present these compounds have limited applications, except in pharmaceutical and biomedical engineering industry. These activators are able to link together different molecules with a mechanism "lock and key".

As for leather tanning their activity mimics the one of chrome salts since very strong bonds and cross-linking is formed implementing the stability of the collagen matrix, avoiding degradation in time.

The fundamental and unprecedented difference between all conventional tanning agents and ALC is that the latter act as "catalysts" or "enzymes", are not retained in the leather after tanning. They stabilize the collagen structure, increase the $\mathrm{Tg}$, and leave no trace giving tanned leather which is devoid chemicals and is thus non-toxic. At present, it is commonly accepted that a tanning agent is such if during tanning it is retained within the collagen matrix. $\mathrm{ACL}$ refuted this definition showing that it is possible to tan hides without the need of any chemical remaining permanently bonded to the skin. This is due to the ability of $A C L$ to react functional groups already present in collagen, creating a level of cross-linking, stabilization adequate and comparable with that obtained with chrome.

$\mathrm{ACL}$ overcome one of the most critical aspects of all alternative tanning systems known today which give leather of lower quality, applicability, price, etc. to chrome leather. ACL are the first real alternative to chrome salts verified to date, as will be further explained bellow.

ACL is representative of a class of organic compounds, which can be easily modified and is under study in order to obtain libraries of molecules, having different performance which can be optimized as a function of the specific type of leather produced (footwear, leather goods, garments, etc.).

Although one ACL is commercially available at very high prices and has been tested, it has been verified that an innovative class of $A C L$ can be produced with optimized characteristics and at competitive prices, especially devised for the leather industry 
(pending patent).

Hides to be treated with ACL protocol may be processed according to standard industrial protocols which is actually simplified with reduction in chemical, water and energy consumption. In fact, $\mathrm{ACL}$ do not require pickling and basification since they have maximum reactivity towards hides at neutral $\mathrm{pH}$ and high quality leather samples have been achieved after only $4 \mathrm{~h}$ (compared to $24 \mathrm{~h}$ with chrome) with $5 \mathrm{w} \%$ of tanning agent without any modification on the equipment employed. This characteristic allows to reduce the consumption of chemical products (acids, bases, $\mathrm{NaCl}$ ), water and energy compared to chrome tanning.

Another important consequence of the non-toxic nature of the tanned leather, is the possibility to recover and recycle ACL tanned organic wastes for the production of high value products such as gelatin and liquid collagen for pharmaceuticals, nutraceutics, pets food, etc.

Chrome tanned scraps are now collected by specialized industries which, after a multistep purification process required to separate chrome from the organic waste, transform the recovered collagen into fertilizers for agriculture. ACL scraps can be processed devoid purification and ideally none of these wastes will be sent to landfill. Tests were carried out both on powder collagen and on hides at different temperatures, $\mathrm{pH}$, concentration, etc. The effect of the tanning by ACL is determined by Differential Scanning Calorimetry (DSC) which measures the temperature at which a material is subject to phase transition; in the case of collagen it measures the decomposition, gelatinization temperature $(\mathrm{Tg})$; higher $\mathrm{Tg}$ give more stable products in time. Chromium salts give the highest $\mathrm{Tg}>100^{\circ} \mathrm{C}$ known today, while all other tanning agents give values around $75-78^{\circ} \mathrm{C}$, with a load of reactants which is often around 25$30 \%$ in weight/weight of leather processed. The possibility to achieve $\operatorname{Tg}>80^{\circ} \mathrm{C}$ seams a limiting value of these technology and would constitute a great advantage in terms of collagen stability.

All newly devised $\mathrm{ACL}$ tested give $\mathrm{Tg}>82-85^{\circ} \mathrm{C}$, and maximum $5 \%$ reagent is required. 


\section{CONCLUSIONS}

In conclusion in this paper we have given a brief overview of some of the most relevant problems inherent with leather manufacturing. In this panorama ACL technology stems as a very promising alternative to tanning agents employed today with significant advantages, such as:

- ACL reagents have been demonstrated to be efficient tanning agents able to tan hides giving characteristics comparable to chrome leather;

- ACL tan without leaving any trace in the final tanned leather which is thus non-toxic; - No chrome is required for tanning. We estimate that if $10 \%$ of the European market where to adopt this technology 400 ton/year of chrome will be substituted by ACL with a significant reduction in toxic waste disposal both liquid and solid.

- Reduction in disposal costs of leather scraps: at present Industries pay over 110 $€ /$ ton to specialized companies which reuse part of the material for fertilizers. These costs will be reduced or avoided when ACL scraps will be available for the production of high value end products.

- Studies are in progress to test ACL waste water treatment with conventional purification systems. So far it has been demonstrated that $\mathrm{ACL}$ are biocompatible with bacteria commonly employed for waste digestion.

\section{REFERENCES}

1. A. Gunasekaran , A. Spalanzani, Int. J. Production Economics 2012, 14, 35-47.

2. a) G.T. Yamamoto, Ö. Şekeroğlu, E.E. Bayramoğlu, Inter. J. Econ. Manag. S. 2011, 1, 37-48; b) cotance.com/socialreporting/SER/ESERItalian.pdf.

3. Eippcb.jrc.ec.europa.eu/reference/BREF/TAN_Published_def.pdf.

4. https://www.unido.org/.../user.../UNIDO_IDR_2013_main_report.pdf.

5. A.D. Covington, Tanning Chemistry. The Science of Leather, Cambridge, RSC Publishing, 2009.

6. W. Scholz, M. Lucas, Water Research 2003, 37, 1859-1867.

7. B.R. Mann, M.M. McMillan: http://nzic.org.nz/ChemProcesses/animal/5c.pdf.

8. J.H. Highberger, J. Am. Chem. Soc. 1939, 61, 2302-2303.

9. J.H. Bowes, R.H. Kenten, Biochem. 1950, 46, 1-8.

10. J.J. Lim, M.H. Shamos, Biopolymers 1974, 13, 1797-1807. 